EXTENDED REPORT

\title{
Pain and high sensitivity $C$ reactive protein in patients with chronic low back pain and acute sciatic pain
}

\author{
T Stürmer, E Raum, M Buchner, K Gebhardt, M Schiltenwolf, W Richter, H Brenner
}

Ann Rheum Dis 2005;64:921-925. doi: 10.1136/ard.2004.027045

\begin{abstract}
See end of article for authors' affiliations

Correspondence to:

Dr Til Stürmer, Division of Pharmacoepidemiology and Pharmacoeconomics, Brigham and Women's Hospital, Harvard Medical School, Boston, MA 02120, USA; til.sturmer@ post.harvard.edu
\end{abstract}

Accepted 27 October 2004

\begin{abstract}
Background: The severity of pain from musculoskeletal disorders might be associated with high sensitivity $C$ reactive protein (hsCRP), a sensitive marker of low grade systemic inflammation.

Objective: To study the association between pain as assessed by a visual analogue scale (VAS) and hsCRP in patients with chronic low back pain and acute sciatic pain.

Methods: Information on pain severity, determinants of hsCRP, and hsCRP values were obtained prospectively at up to 10 time points during six months in 72 consecutive patients (mean age 43.3 years; $59.7 \%$ female): 41 with chronic low back pain and 31 with acute sciatic pain. The association between severity of pain and raised (highest quartile) hsCRP values at any time point was estimated by multivariable logistic regression using generalised estimating equations to adjust odds ratios (OR) and their confidence intervals (Cl) for intraindividual dependence of measurements.

Results: Mean intensity of pain (VAS 0-10) at baseline was 4.9 and 5.5 in patients with chronic low back and acute sciatic pain, respectively. Highest $v$ lowest tertile of average intensity of pain during the last 24 hours was associated with increased hsCRP levels among patients with acute sciatic pain (adjusted $\mathrm{OR}=3.4(95 \% \mathrm{Cl}, 1.1$ to 10$)$, but not in patients with chronic low back pain (adjusted $\mathrm{OR}=0.87(0.25$ to 3.0)).

Conclusions: Mean intensity of pain during the previous 24 hours as assessed by VAS was independently associated with high levels of hsCRP in patients with acute sciatic pain but not in those with chronic low back pain.
\end{abstract}

A lthough musculoskeletal diseases, including osteoarthritis, inherently lack the large scale systemic inflammatory response that is the hallmark of rheumatoid arthritis, some of them seem to be associated with a low grade systemic inflammatory response. ${ }^{1-4}$ Furthermore, we recently found that the severity of pain was associated with serum concentrations of high sensitivity $C$ reactive protein (hsCRP), a sensitive marker of low grade systemic inflammation, in patients with osteoarthritis. ${ }^{5}$

Low back pain is of major public health importance but little is known about the predictors of chronic and acute pain severity. ${ }^{67}$ As with osteoarthritis, degenerative changes are one of the causes of chronic low back pain, and it might be hypothesised therefore that the severity of pain is associated with hsCRP levels. Raised hsCRP values in comparison with age and sex matched controls have been observed in patients with acute sciatic pain. ${ }^{8}$ This elevation might be caused by inflammation of local soft tissues leading to pain and a subclinical increase in hsCRP.

Besides acute infections and known systemic inflammatory conditions, characteristics such as age, body mass index, diabetes, smoking, and alcohol consumption are known or suspected to influence hsCRP levels. ${ }^{9}{ }^{10}$ As many of these characteristics are also likely to be associated with pain perception, they need to be taken into account in the interpretation of the relation between pain and hsCRP.

Our aim in this study was to assess the association between pain as measured by visual analogue scales and hsCRP values in cohorts of patients with chronic low back pain and acute sciatic pain.

\section{METHODS}

Starting in April 2002, consecutive patients with chronic low back pain and acute sciatic pain were recruited by a physician (KG) at the orthopaedic clinic of the University of Heidelberg,
Germany. Patients had to be older than 20 years of age and fluent in German. Patients with cancer, chronic inflammatory diseases (rheumatoid arthritis, colitis), use of steroids, and a history of psychiatric illness were excluded. All patients gave written informed consent. The study protocol was approved by the ethics committee of the faculty of medicine of the University of Heidelberg.

Patients with chronic low back pain were recruited at the beginning of an outpatient functional restoration programme offered at the orthopaedic clinic. Inclusion criteria were low back pain attributable to the spine for at least six weeks and not having led to inability to work for more than six months during the past 12 (owing to pertinent legislation with respect to insurance benefits).

Patients with acute sciatic pain were recruited on the day of or the first day after admission. Acute sciatic pain was defined as pain radiating below the knee with a maximum duration of eight weeks. To be eligible, patients had to have a positive straight leg raising test during clinical examination and to show evidence of lumbar disc prolapse on magnetic resonance imaging. Patients with signs of compression of the spinal cord, pronounced muscle weakness, a spinal stenosis, or previous surgery were not eligible.

Patients willing and consenting to participate received a questionnaire asking for information on sociodemographic factors, height and weight, and comorbidity, as well as on pain and various factors possibly associated with hsCRP levels, including therapeutic drug use, alcohol consumption, and smoking during the previous 24 hours. All patients underwent a physical examination, and a non-fasting venous blood sample was drawn.

Abbreviations: $B M I$, body mass index; hsCRP, high sensitivity $C$ reactive protein; VAS, visual analogue scale 


\section{Follow up}

The patients were asked to complete short questionnaires asking for information on pain and various factors that could be associated with acute changes in hsCRP levels, including drug use, alcohol consumption, and smoking during the last 24 hours. They had a venous blood sample drawn on days 3 , 7, 10, 14, 17, and 21 as well as after two, three, and six months. Questionnaires and blood samples until day 21 and after six months were conditional on the patient being available for blood sampling at the university hospital, whereas questionnaires at months 2 and 3 were mailed to participants and included a kit for venopuncture to be done during an ambulatory visit to a general practitioner.

\section{Severity of pain}

Average severity of pain during the previous 24 hours was assessed using a visual analogue scale (VAS). ${ }^{11}$ Under a heading asking the subject to make a cross on the line corresponding to the severity of low back pain between 0 (no pain at all) and 10 (pain that you cannot imagine getting any worse), horizontal bars of $10 \mathrm{~cm}$ length with vertical bars numbered from 0 to 10 were presented. The VAS score was measured in $\mathrm{mm}$ from the left hand vertical bar to a vertical line through the midpoint of the corresponding marking (usually a cross).

\section{High sensitivity CRP}

Serum samples were stored at $-80^{\circ} \mathrm{C}$ and analysed after completion of the follow up at the research laboratory of the orthopaedic university hospital. hsCRP was measured by nephelometric method using a commercial kit (NA-latex CRP, Dade Behring Werke, Marburg, Germany), calibrated with the WHO reference standard 85/506.

\section{Covariates}

Age, sex, body mass index (BMI; weight $(\mathrm{kg})$ divided by height squared $(\mathrm{m})$ ), and a history of diabetes were assessed at baseline and assumed to be constant over time. In addition to severity of pain, covariates likely to be associated with acute changes in hsCRP and possibly varying during follow up were assessed on every questionnaire. Specifically, these included smoking, alcohol consumption, use of diuretics, and use of analgesic drugs and topical steroid injections during the previous 24 hours.

\section{Statistical analyses}

We first described the patients with respect to sociodemographic and lifestyle factors. As serum hsCRP values were not normally distributed, log transformed (geometric) means were then calculated and tabulated according to tertiles of severity of average pain derived from the observed distributions. Finally, bivariate and multivariable logistic regression models with an hsCRP value above the 75 th centile of the observed distribution (2.90 and $2.05 \mathrm{mg} / \mathrm{l}$ in patients with chronic low back pain and acute sciatic pain, respectively) as dependent variable were used to assess the independent impact of pain severity on raised serum hsCRP concentrations. Owing to the different hsCRP cut off points used for patients with chronic low back pain and acute sciatic pain (necessary because of the different distribution of hsCRP values in these two groups of patients), we could not formally test for effect modification. All time points of follow up measurements were combined, controlling for intraindividual dependence of measurements using generalised estimating equations. All covariates described above were included in the multivariable models. We checked the final models for co-linearity according to the Belsley, Kuh, and Welsch criteria. All analyses were carried out using the Statistical Analysis System (SAS, release 8.02, Cary, North Carolina, USA).

\section{RESULTS}

In all, 72 patients could be recruited, 41 with chronic low back pain and and 31 with acute sciatic pain (table 1). Patients with chronic low back pain were younger than those with acute sciatic pain. While the number of women and men was almost equal in patients with acute sciatic pain, almost two thirds of the patients with chronic low back pain were women. Obesity (BMI $\geqslant 30 \mathrm{~kg} / \mathrm{m}^{2}$ ), current smoking, and alcohol consumption during the previous 24 hours were all more prevalent in patients with chronic low back pain than in those with acute sciatic pain.

In table 2 we describe the participation in the follow up examinations. Participation until day 10 was almost complete but fell for days 14 to 21 , mainly because of shorter durations of hospital admission. The questionnaire based assessments after two and three months as well as the final assessment after six months were again almost complete. The final column gives the overall number of observations that were

\begin{tabular}{|c|c|c|c|}
\hline & Total & $\begin{array}{l}\text { Chronic low back } \\
\text { pain }\end{array}$ & Acute sciatic pain \\
\hline $\mathrm{n}$ & 72 & 41 & 31 \\
\hline Age (years) (mean (SD)) & $43.3(10.2)$ & $42.2(8.3)$ & $44.8(12.4)$ \\
\hline Female sex (n (\%)) & $43(59.7 \%)$ & $27(65.8 \%)$ & $16(51.6 \%)$ \\
\hline BMI $\left(\mathrm{kg} / \mathrm{m}^{2}\right)($ mean $(S D))$ & $27.0(5.7)$ & $27.7(6.8)$ & $26.1(3.8)$ \\
\hline$<25$ & $29(40.3)$ & $17(41.5)$ & $12(38.7)$ \\
\hline 25 to $<30$ & $30(41.7)$ & $15(36.6)$ & $15(48.4)$ \\
\hline$\geqslant 30$ & $13(18.0)$ & $9(21.9)$ & $4(12.9)$ \\
\hline \multicolumn{4}{|l|}{ Smoking (n (\%)) } \\
\hline Never & $26(36.1 \%)$ & $15(36.6 \%)$ & $11(35.5 \%)$ \\
\hline Former & $21(29.2 \%)$ & $9(21.9 \%)$ & $12(38.7 \%)$ \\
\hline Current & $25(34.7 \%)$ & $17(41.5 \%)$ & $8(25.8 \%)$ \\
\hline \multicolumn{4}{|c|}{ Education (formal schooling) (n (\%)) } \\
\hline Up to 9 years & $33(45.8 \%)$ & $19(46.3 \%)$ & $14(45.2 \%)$ \\
\hline 10 years & $20(27.8 \%)$ & $13(31.7 \%)$ & $7(22.6 \%)$ \\
\hline 11 or more years & $19(26.4 \%)$ & $9(22.0 \%)$ & $10(32.2 \%)$ \\
\hline Alcohol consumption* (n (\%)) & $16(22.2 \%)$ & $11(26.8 \%)$ & $5(16.1 \%)$ \\
\hline \multicolumn{4}{|l|}{ Comorbidity (n (\%)) } \\
\hline Hypertension & $8(11.1 \%)$ & $2(4.9 \%)$ & $6(19.1 \%)$ \\
\hline Diabetes & $1(1.4 \%)$ & $1(2.4 \%)$ & 0 \\
\hline
\end{tabular}


Table 2 Description of follow up examinations

\begin{tabular}{|c|c|c|c|c|c|c|c|c|c|c|c|}
\hline & Baseline & Day 3 & Day 7 & Day 10 & Day 14 & Day 17 & Day 21 & Mo 2 & Mo 3 & Mo 6 & Obs \\
\hline \multicolumn{12}{|l|}{ Patients ( $\mathrm{n}$ ) } \\
\hline Chronic low back pain & 41 & 39 & 41 & 41 & 36 & 34 & 0 & 38 & 35 & 38 & 345 \\
\hline Acute sciatic pain & 31 & 31 & 31 & 30 & 24 & 13 & 7 & 28 & 30 & 30 & 255 \\
\hline \multicolumn{12}{|l|}{ Exclusion criteria } \\
\hline Steroids & - & - & - & - & - & - & - & - & 1 & - & 1 \\
\hline Antibiotics & - & - & 1 & 2 & 2 & - & - & 2 & - & 1 & 8 \\
\hline Chemotherapy & - & - & - & - & - & - & - & - & - & 1 & 1 \\
\hline Unsynchronised QQ-blood* & - & - & - & - & - & - & - & 3 & 4 & - & 7 \\
\hline Surgery & - & - & - & - & - & - & - & - & 3 & 5 & 8 \\
\hline Cancer & - & - & - & - & - & - & - & - & - & 1 & 1 \\
\hline$C R P>100 \mathrm{mg} / \mathrm{l}$ & - & - & - & - & 1 & - & - & - & - & - & 1 \\
\hline \multicolumn{12}{|l|}{ Patients analysed $\dagger$} \\
\hline Chronic low back pain & 41 & 39 & 40 & 40 & 36 & 35 & 0 & 33 & 34 & 37 & 335 \\
\hline Acute sciatic pain & 31 & 31 & 31 & 29 & 22 & 13 & 7 & 28 & 23 & 24 & 239 \\
\hline
\end{tabular}

*Blood not drawn within \pm 2 days of the questionnaire being filled in.

†Some observations met multiple exclusion criteria; three additional observations without CRP values and pain measurement, respectively

CRP, C reactive protein; Mo, month; Obs, observations.

available for analyses on the association of severity of pain with hsCRP levels.

hsCRP values according to average severity of pain during the previous 24 hours in patients with chronic low back pain are presented in table 3 . The table contains information on both the geometric mean and the proportion of observations having values above $2.90 \mathrm{mg} / \mathrm{l}$, corresponding to the 75 th centile of the observed values. The geometric mean of hsCRP was $1.4 \mathrm{mg} / \mathrm{l}$ in the highest pain category, compared with $1.3 \mathrm{mg} / \mathrm{l}$ in the middle and lowest pain category. There was a monotonic increase in the proportion of observations with high hsCRP values, from $16.8 \%$ in the lowest pain category to $33.3 \%$ in the highest category. The unadjusted odds ratio (OR) for a raised hsCRP contrasting the highest to the lowest pain category was 2.5 with $95 \%$ confidence interval (CI) ranging from 0.70 to 8.8 . However, after adjustment for confounding, mainly by body mass index, the odds ratio for this contrast was reduced to 0.87 (95\% CI, 0.25 to 3.0 ).

In table 4, we present the corresponding analyses for patients with acute sciatic pain. The geometric mean hsCRP values were lower than in patients with chronic low back pain, but the differences between the pain categories were more pronounced. In the highest category, the geometric mean hsCRP level was $1.3 \mathrm{mg} / \mathrm{l}$, compared with $0.8 \mathrm{mg} / \mathrm{l}$ in the lowest pain category. Correspondingly, in the highest pain category the percentage of observations with raised hsCRP values $(40.6 \%)$ was almost twice that observed in the lowest pain category $(20.5 \%)$. The unadjusted odds ratio for this contrast was 2.7 (95\% CI, 1.3 to 5.5). After adjustment for confounding, this association was more pronounced, with an odds ratio of 3.4 (95\% CI, 1.1 to 10$)$.

\section{DISCUSSION}

In this prospective cohort study with repeated measurements of various dimensions of pain, hsCRP levels, and factors likely to influence hsCRP levels-specifically designed to address the hypothesis that the severity of pain is an independent predictor of subclinical systemic inflammation-we observed a strong association between pain and hsCRP levels in patients with acute sciatic pain, but not in patients with chronic low back pain. Although it seems too early to speculate on the clinical significance of our finding, it might shed light on distinct pathophysiological mechanisms of pain in these two groups of patients (for example, inflammatory in patients with acute sciatic pain and non-inflammatory in patients with chronic back pain) and could therefore eventually lead to better pain management in both groups of patients.

The results in patients with acute sciatic pain support our previous finding of an association between pain and hsCRP levels in patients with advanced osteoarthritis. ${ }^{5}$ Thus hsCRP might be a marker of severity of pain in patients with specific musculoskeletal disorders.

There is increasing evidence that local musculoskeletal disorders result in a subclinical systemic inflammatory response. $^{512-15}$ The sensation of pain in patients with osteoarthritis is at least closely linked to, or might even be the result of, local inflammatory processes. ${ }^{16}{ }^{17}$ Higher levels

Table 3 High sensitivity $\mathrm{C}$ reactive protein according to average severity of pain during the last 24 hours in patients with chronic low back pain

\begin{tabular}{|c|c|c|c|c|}
\hline \multirow{4}{*}{$\begin{array}{l}\text { Pain severity } \\
\text { (VAS)* }^{*}\end{array}$} & \multicolumn{4}{|c|}{ High sensitivity $C$ reactive protein } \\
\hline & \multirow{3}{*}{$\begin{array}{l}\text { Geometric mean } \\
(95 \% \mathrm{CI})\end{array}$} & \multicolumn{3}{|c|}{ Raised values (>2.9 mg/l) } \\
\hline & & \multirow[b]{2}{*}{$n(\%)$} & \multicolumn{2}{|l|}{ OR $(95 \% \mathrm{Cl}) \dagger$} \\
\hline & & & Unadjusted & Adjusted $\ddagger$ \\
\hline $\begin{array}{l}\leqslant 2.3 \\
>2.3 \text { to } 4.5 \\
>4.5\end{array}$ & $\begin{array}{l}1.3(0.8 \text { to } 1.9) \\
1.3(0.9 \text { to } 2.0) \\
1.4(0.9 \text { to } 2.4)\end{array}$ & $\begin{array}{l}19(16.8) \\
26(24.8) \\
39(33.3)\end{array}$ & $\begin{array}{l}1.0 \text { (reference) } \\
1.6(0.48 \text { to } 5.6) \\
2.5(0.70 \text { to } 8.8)\end{array}$ & $\begin{array}{l}1.0 \text { (reference) } \\
1.7(0.61 \text { to } 4.8) \\
0.87(0.25 \text { to } 3.0)\end{array}$ \\
\hline
\end{tabular}

*Tertiles of average pain severity during the previous 24 hours from visual analogue scale ranging from 0 (none) to 10 (extreme).

†Odds ratio and $95 \%$ confidence interval for high sensitivity $C$ reactive protein $>2.90 \mathrm{mg} / \mathrm{l}$ (above 75 th centile of observed values) from multivariable logistic regression model adjusting for intraindividual dependence of events using generalised estimating equations.

fFor age (continuous), sex, smoking (three categories), alcohol consumption during the previous 24 hours (yes/ no), body mass index (continuous), diabetes (yes/no), and use of analgesic drugs during the previous 24 hours. $\mathrm{Cl}$, confidence interval; OR, odds ratio; VAS, visual analogue scale. 
Table 4 High sensitivity $C$ reactive protein according to average severity of pain during the previous 24 hours in patients with acute sciatic pain

\begin{tabular}{|c|c|c|c|c|}
\hline \multirow[b]{4}{*}{ Pain severity (VAS)* } & \multicolumn{4}{|c|}{ High sensitivity $C$ reactive protein } \\
\hline & \multirow{3}{*}{$\begin{array}{l}\text { Geometric mean } \\
(95 \% \mathrm{CI})\end{array}$} & \multicolumn{3}{|c|}{ Raised values (>2.05 mg/l) } \\
\hline & & \multirow[b]{2}{*}{$\mathrm{n}(\%)$} & \multicolumn{2}{|l|}{ OR $(95 \%$ Cl)† } \\
\hline & & & Unadjusted & Adjusted¥ \\
\hline $\begin{array}{l}\leqslant 2.0 \\
>2.0 \text { to } 4.0 \\
>4.0\end{array}$ & $\begin{array}{l}0.8(0.5 \text { to } 1.1) \\
0.8(0.6 \text { to } 1.1) \\
1.3(0.9 \text { to } 2.0)\end{array}$ & $\begin{array}{l}18(20.5) \\
14(17.3) \\
26(40.6)\end{array}$ & $\begin{array}{l}1.0 \text { (reference) } \\
0.81 \text { (0.37 to } 1.8) \\
2.7(1.3 \text { to } 5.5)\end{array}$ & $\begin{array}{l}1.0 \text { (reference) } \\
0.83(0.36 \text { to } 1.9) \\
3.4(1.1 \text { to } 10)\end{array}$ \\
\hline
\end{tabular}

*Tertiles of average pain severity during the previous 24 hours from visual analogue scale ranging from 0 (none) to 10 (extreme).

†Odds ratio and $95 \%$ confidence interval for high sensitivity $\mathrm{C}$ reactive protein $>2.05 \mathrm{mg} / \mathrm{l}$ (above 75 th centile of observed values) from multivariable logistic regression model adjusting for intraindividual dependence of events using generalised estimating equations.

fFor age (continuous), sex, smoking (three categories), alcohol consumption during the previous 24 hours (yes/ no), body mass index (continuous), use of diuretics, and use of analgesic drugs and topical steroid injections during the previous 24 hours.

$\mathrm{Cl}$, confidence interval; OR, odds ratio; VAS, visual analogue scale.

of both interleukin $1 \beta$ and tumour necrosis factor $\alpha$ have also been detected in sera from patients with other painful conditions, such as cervicogenic headache. ${ }^{18}$ Tissue injury is known to result in the release of a variety of inflammatory mediators including ions, bradykinin, histamine, 5-hydroxytryptamine, ATP, and nitric oxide. ${ }^{19}$ The activation of the arachidonic pathway may then lead to the production of prostanoids and leukotrienes and recruited immune cells may release further mediators, including cytokines and growth factors. ${ }^{18}$

In contrast to patients with acute sciatic pain and to our previous observation in patients with osteoarthritis, ${ }^{5}$ the association between pain and hsCRP was almost exclusively explained by confounding in patients with chronic low back pain. This confounding reflected the strong association of this type of pain with obesity or body mass index, important independent predictors of raised hsCRP levels. Overweight is likely to be more strongly associated with low back pain ${ }^{6} 720$ than with osteoarthritis ${ }^{21}$ or acute sciatic pain. In patients with chronic low back pain, pain severity might thus be more strongly related to overweight and psychological factors than to pathophysiological changes leading to low grade systemic inflammation than would be the case in patients with acute sciatic pain.

Our study did not include healthy controls. The geometric mean serum hsCRP concentrations in our patients with chronic low back pain and acute sciatic pain were, however, well within the range observed in apparently healthy individuals in Germany. ${ }^{22}$ The generally higher values in patients with chronic low back pain compared with those with acute sciatic pain can mainly be explained by the higher mean body mass index observed in the former group.

Despite a wide variety of inflammatory markers now available for analysis which might add to the interpretation of the data, we focused on high sensitivity $\mathrm{C}$ reactive protein as a marker of subclinical systemic inflammation, as it has well established epidemiological and clinical determinants, ${ }^{9}{ }^{10}$ little diurnal variation, ${ }^{23}$ and moderate within person variability, allowing long term prediction of disease. ${ }^{22}$ We then assessed independent determinants of this marker in a well described population of 72 consecutive patients who were recruited using a standardised protocol and interview. In our analyses, we took known and suspected determinants of serum hsCRP into account using multivariable regression methods.

The limitations of our study need to be taken into account when interpreting the results. Although widely used to assess the intensity of pain in clinical and epidemiological settings, the measurement of pain using a visual analogue scale is influenced by various factors associated with the perception of pain. ${ }^{24}{ }^{25}$ Nevertheless, pain is always subjective and the observed associations provide evidence that the subjective phenomenon is associated with markers of low level systemic inflammation, at least in patients with acute sciatic pain.

Information on weight and height was based on self report, and weight might be prone to intentional or unintentional underreporting, especially in obese patients. All patients were seen repeatedly by the study physician, however, who had access to the records (including the measured weight), collected the questionnaires, and checked the data quality. Thus important discrepancies between self reported and measured weight would probably have been picked up before data entry. Furthermore, the association between BMI and hsCRP levels in our study was very similar to that reported from other studies in which height and weight were actually measured. Nevertheless, some potential residual confounding owing to less than perfect data on body weight cannot be ruled out, though such residual confounding would be very unlikely to explain the strongly divergent results found for the two patient groups in this study.

The association between obesity and hsCRP could be influenced by factors not taken into account in our analyses. Depressive mood, for example, has been observed to be associated with hsCRP levels in obese but not normal weight middle aged men, ${ }^{26}$ and is likely to be strongly associated with pain perception. Larger studies would be needed to address such possible interactions between pain and hsCRP in more detail.

Despite the fact that the two groups of patients were relatively small for an epidemiological study (but well within the scope of clinical studies), our analyses were based on up to 10 time points per patient and a total of 574 blood samples and questionnaires.

\section{Conclusions}

Mean intensity of pain during the previous 24 hours as assessed by VAS was independently associated with high levels of hsCRP in patients with acute sciatic pain but not in those with chronic low back pain. Pain severity in patients with acute sciatic pain may be more closely linked to inflammatory changes than in patients with chronic low back pain.

\section{ACKNOWLEDGEMENTS}

The study was supported by a research grant from the Orthopaedic Clinic, University of Heidelberg. 


\section{Authors' affiliations}

T Stürmer, E Raum, H Brenner, Department of Epidemiology, German

Centre for Research on Aging, Heidelberg, Germany

M Buchner, K Gebhardt, M Schiltenwolf, W Richter, Orthopaedic

Clinic, University of Heidelberg

\section{REFERENCES}

1 Wolfe $\mathrm{F}$. The C-reactive protein but not erythrocyte sedimentation rate is associated with clinical severity in patients with osteoarthritis of the knee or hip. J Rheumatol 1997:24:1486-8.

2 Sharif $M$, Elson CJ, Dieppe PA, Kirwan JR. Elevated serum C-reactive protein levels in osteoarthritis [letter]. Br J Rheumatol 1997;36:140-1.

3 Spector TD, Hart DJ, Nandra D, Doyle DV, Mackillop N, Gallimore JR, et al. Low-level increases in serum C-reactive protein are present in early osteoarthritis of the knee and predict progressive disease. Arthritis Rheum 1997;40:723-7.

4 Conrozier T, Chappuis-Cellier C, Richard M, Mathieu P, Richard S, Vignon E. Increased serum C-reactive protein levels by immunonephelometry in patients with rapidly destructive hip osteoarthritis. Rev Rheum Engl Ed 1998:65:759-65.

5 Sturmer T, Brenner H, Koenig W, Gunther KP. Severity and extent of osteoarthritis and low grade systemic inflammation as assessed by high sensitivity C-reactive protein. Ann Rheum Dis 2004;63:200-5.

6 Heliovaara M, Makela M, Knekt $P$, Impivaara O, Aromaa A. Determinants of sciatica and low-back pain. Spine 1991;16:608-14.

7 Fransen M, Woodward M, Norton R, Coggan C, Dawe M, Sheridan N. Risk factors associated with the transition from acute to chronic occupational back pain. Spine 2002;27:92-8

8 Le Gars L, Borderie D, Kaplan G, Berenbaum F. Systemic inflammatory response with plasma $C$-reactive protein elevation in disk-related lumbosciatic syndrome. Joint Bone Spine 2000;67:452-5.

9 Frohlich M, Imhof A, Berg G, Hutchinson WL, Pepys MB, Boeing $\mathrm{H}$, et al. Association between $\mathrm{C}$-reactive protein and features of the metabolic syndrome: a population-based study. Diabetes Care 2000;23:1835-9.

10 Imhof A, Froehlich M, Brenner H, Boeing H, Pepys MB, Koenig W. Effect of alcohol consumption on systemic markers of inflammation. Lancet 2001;357:763-7.

11 Paul-Dauphin A, Guillemin F, Virion JM, Briancon S. Bias and precision in visual analogue scales: a randomized controlled trial. Am J Epidemiol 1999; 150:1117-27.
12 Saxne T, Lindell M, Mansson B, Petersson IF, Heinegard D. Inflammation is a feature of the disease process in early knee joint osteoarthritis [letter] Rheumatology (Oxford) 2003;42:903-4.

13 Hrycaj PZ. Systemic inflammation in osteoarthritis [letter]. Ann Rheum Dis 2004;63:750-1.

14 Sowers M, Jannausch M, Stein E, Jamadar D, Hochberg M, Lachance L. C reactive protein as a biomarker of emergent osteoarthritis. Osteoarthritis Cartilage 2002; 10:595-601.

15 So AK, Varisco PA, Kemkes-Matthes B, Herkenne-Morard C, Chobaz-Peclat V, Gerster JC, et al. Arthritis is linked to local and systemic activation of coagulation and fibrinolysis pathways. J Thromb Haemost 2003;1:2510-15.

16 Merritt JL. Soft tissue mechanisms of pain in osteoarthritis. Semin Arthritis Rheum 1989;18(suppl 2):51-6.

17 Schumacher R. The role of inflammation and crystals in the pain of osteoarthritis. Semin Arthritis Rheum 1989;18(suppl 2):81-5.

18 Martelletti P. Proinflammatory pathways in cervicogenic headache. Clin Exp Rheumatol 2000;18(suppl 19):S33-8.

19 Kidd BL, Urban LA. Mechanisms of inflammatory pain. Br J Anaesth 2001:87:3-11.

20 Sturmer T, Luessenhoop S, Neth A, Soyka M, Karmaus W, Toussaint R, et al. Construction work and low back disorder; preliminary findings of the Hamburg construction worker study. Spine 1997;22:2558-63.

21 Sturmer T, Gunther KP, Brenner H. Obesity, overweight and patterns of osteoarthritis: the Ulm Osteoarthritis Study. J Clin Epidemiol 2000;53:307-13.

22 Koenig W, Sund M, Frohlich M, Lowel H, Hutchinson WL, Pepys MB. Refinement of the association of serum $\mathrm{C}$-reactive protein concentration and coronary heart disease risk by correction for within-subject variation over time: the MONICA Augsburg studies, 1984 and 1987. Am J Epidemiol 2003;158:357-64

23 Meier-Ewert HK, Ridker PM, Rifai N, Price N, Dinges DF, Mullington JM. Absence of diurnal variation of $C$-reactive protein concentrations in healthy human subjects. Clin Chem $2001 ; 47: 426-30$.

24 Woolf CJ, Decosterd I. Implications of recent advances in the understanding of pain pathophysiology for the assessment of pain in patients. Pain 1999;(suppl 6): $5141-7$

25 Katz J, Melzack R. Measurement of pain. Surg Clin North Am 1999:79:231-52.

26 Ladwig KL, Marten-Mittag B, Lowel H, Doring A, Koenig W. Influence of depressive mood on the association of CRP and obesity in 3205 middle aged healthy men. Brain Behav Immun 2003;17:268-75. 